\title{
EDITORIAL
}

\section{Children Vaccination of COVID-19}

Sadia Choudhury Shimmi1*, M. Tanveer Hossain Parash ${ }^{1,2}$

\author{
1 Department of Biomedical Sciences, \\ Faculty of Medicine and Health Sciences, \\ Universiti Malaysia Sabah, Kota Kinabalu, \\ Sabah, Malaysia \\ ${ }^{2}$ Borneo Medical and Health Research Centre, \\ Faculty of Medicine and Health Sciences, \\ Universiti Malaysia Sabah, Kota Kinabalu, \\ Sabah, Malaysia
}

\section{*Corresponding author's email: shimmi_cmc40@ums.edu.my}

The Delta variant is currently the highly contagious predominant variant of the SARSCoV-2 virus worldwide that causes severe illness more than the previous variants in unvaccinated people (CDC, 2021). At a White House briefing, the National Institute of Allergy and Infectious Diseases director, Anthony Fauci, predicted that there would be an increase in the number of child hospitalisation proportionate to the increased number of children getting infected with the Delta variant (Press briefing White House, 2021). In response to this situation, the FDA (U.S. Food and Drug Administration) approved Pfizer-BioNTech and Moderna vaccines for children aged $12-17$ years. Vaccines in children aged $5-11$ years are currently under clinical trial (Sick-Samuels \& Messina, 2021).

The United States of America, along with Israel, are the pioneers in vaccinating children. In the United Kingdom (UK), the Joint Committee on Vaccination and Immunisation (JCVI) does not recommend vaccinating healthy children aged $12-15$ years old on health grounds alone. The committee believes that vaccination in children would bring meagre gain compared to the threat of the infection. So, they recommended vaccination in 12 - 15-year-olds who are at increased risk of severe COVID-19 disease and hospitalisation in those with severe neuro-disabilities, immunosuppression, Down Syndrome, haematological malignancy, sickle cell disease, type 1 diabetes, congenital heart disease, other health conditions as described under 
"COVID-19 clinical risk groups for children aged twelve to fifteen years" profound and multiple learning disabilities, severe learning disabilities, or on GP the learning disability register, those who are household contacts of people of any age who are immunosuppressed and those turning eighteen in the next three months (Department of Health and Social Care, 2021).

Until the recent surge of the Delta variant, European Union (EU) countries like Italy, Germany, France, Poland, and Denmark followed the same guideline. However, when this editorial was being drafted (7 September 2021), most EU countries started vaccination in children 12 - 17 years old age group where Sweden has started giving appointments. Meanwhile, many non-EU (Norway and Switzerland), American (Canada and Chile), Middle-East (Israel, Dubai, and Saudi Arabia), and Asian countries (Singapore, Philippines, Hongkong, and Japan) have either started or approved vaccination in the same age group (Smith, 2021).

In Malaysia, the number of COVID-19 cases involving children under the age of seventeen (17) was 82,341 in the period 29th January 2020 until 31st May 2021 (Ministry of Health, 2021). The most affected age group was $13-17$ years (38.38\%), followed by the age group 7 - 12 years (32.61\%). In Sabah, during the third week of August 2021, around 6,300 children aged seventeen years and below were tested positive (Peter, 2021). The incidence of COVID-19 cases until the emergence of the Delta variant was very low in Malaysia. Hence, the Clinical Guidelines on COVID-19 Vaccination for Adolescents (12 - 17 Years) published in July 2021 by the Ministry of Health $(\mathrm{MOH})$ Malaysia, recommended: "Adolescents with underlying medical conditions are at an increased risk for severe COVID-19 and should be prioritised to receive COVID-19 vaccine". At present, the $\mathrm{MOH}$ has instructed parents to register their children aged 12-17 years for vaccination (Ministry of Health, 2021).
Before the emergence of the Delta variant, scientists were divided in their opinion whether children below seventeen years should be vaccinated for COVID-19 or not. Few researchers support delaying children's vaccination based on insufficient evidence on the safety of vaccination in children, especially on the rare side effects (Lo Re et al., 2021). The risk-benefit ratio is not significant as the severe form of COVID-19 is less in children in comparison to adults. They also raised the issue of global inequity (Wilkinson et al., 2021).

On the contrary, few researchers consider delaying vaccination in theyounger population as illogical. They justified vaccination in children as it protects them from the danger of suffering and death from infection, safeguard others, and promotes children's well-being by curtailing the necessity for limitations or disturbances to their lives owing to the failure to curb infection spread (Skelton \& Forsberg, 2021). Medical authorities like the European Medicines Agency, Health Canada, and the US Centers for Disease Control and Prevention had judged "COVID-19 vaccines to be safe and effective for children" (Wilkinson et al., 2021).

Vaccines are the critical elements to curb the coronavirus virus spread and decrease severe disease. Vaccination in children aged twelve to seventeen years would improve the vaccination coverage to achieve herd immunity and restrain the virus from spreading and evolving to a new variant.

\section{REFERENCES}

CDC. (2021, 26 August). Delta variant: What we know about the science. https://www.cdc. gov/coronavirus/2019-ncov/variants/deltavariant.html

Department of Health and Social Care. (2021). JCVI statement on COVID-19 vaccination of children aged 12 to 15 years: 3 September 2021. GOV.UK. https://www.gov.uk/ government/publications/jcvi-statementseptember-2021-covid-19-vaccinationof-children-aged-12-to-15-years/jcvistatement-on-covid-19-vaccinationof-children-aged-12-to-15-years-3september-2021 
Lo Re, V., 3rd, Klungel, O. H., Chan, K. A., Panozzo, C. A., Zhou, W., \& Winterstein, A. G. (2021). Global COVID-19 vaccine rollout and safety surveillance-how to keep pace. BMJ (Clinical research ed.), 373, n1416. https://doi. org/10.1136/bmj.n1416

Ministry of Health. (2021). Clinical guidelines on COVID-19 vaccination for adolescents (12 17 years) in Malaysia. https://covid-19.moh. gov.my/garis-panduan/garis-panduankkm/ANNEX_48c_CLINICAL_GUIDE_TO_ COVID-19_VACCINATION_IN_CHILDREN_n_ ADOLESCENTS_13082021.pdf

Ministry of Health. (2021). COVID-19 cases reported among children. https://covid-19.moh.gov. my/semasa-kkm/2021/06/covid-19-casesreported-among-children

Peter, A. (2021, 27 August). 2,126 babies, children infected in a week.Daily Express Online.http:// www.dailyexpress.com.my/news/176947/2126-babies-children-infected-in-a-week/

Press briefing by White House COVID-19 response team and public health officials. (2021, 12 Aug). The White House. https:// whitehouse.gov/briefing-room/pressbriefings/2021/08/12/press-briefing-bywhite-housecovid-19-response-team-andpublic-health-officials
Sick-Samuels, A. C., \& Messina, A. (2021). COVID-19 Vaccine: What parents need to know. Health. https://www.hopkinsmedicine.org/health/ conditions-and-diseases/coronavirus/ covid19-vaccine-what-parents-need-toknow

Skelton, A., \& Forsberg, L. (2021, 13 May). 3 Reasons for making COVID-19 vaccination mandatory for children. Conversation. https://theconversation.com/3-reasons-formaking-covid-19-vaccination-mandatoryfor-children-160589.

Smith, I. (2021, 3 September). COVID vaccines: Which countries are vaccinating children over 12 and how do they compare? euronews.next. https://www.euronews. com/next/2021/09/03/covid-vaccine-forchildren-who-in-europe-is-leading-the-race Wilkinson, D., Finlay, I., Pollard, A. J., Forsberg, L., \& Skelton, A. (2021). Should we delay COVID-19 vaccination in children? BMJ, 374, n1687. https://doi.org/10.1136/bmj.n1687 
